
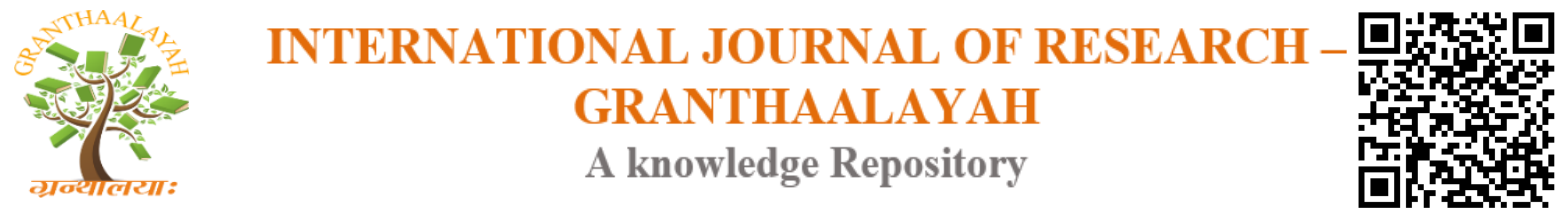

Science

\title{
STUDY AND SIMULATION OF PARTIAL DISCHARGE OF DIFFERENT INSULATORS
}

\author{
Khushboo Patareya ${ }^{1}$, Professor Arun Pachori ${ }^{2}$ \\ ${ }^{1}$ Research scholar, Fourth Semester ME (High Voltage Engg.), Jabalpur Engineering College, \\ Jabalpur (M.P) 482011, India \\ ${ }^{2}$ Associate Professor, Department of Electrical Engineering, Jabalpur Engineering College, \\ Jabalpur (M.P) 482011, India
}

\begin{abstract}
In this paper, we are studying about partial discharge of insulator with various parameters simulated in MATLAB. There are many types of insulator available in markets which have some impurities. The partial discharges are occurred due to presence of air impurity or void in the insulating material. The insulation failure occurs in high voltage power equipment's due to Partial discharges, which readily generates at void or rough conductor profiles of equipment's.

Keywords: Partial Discharge; Insulator; Insulation Materials.

Cite This Article: Khushboo Patareya, and Arun Pachori. (2018). "STUDY AND SIMULATION OF PARTIAL DISCHARGE OF DIFFERENT INSULATORS." International Journal of Research - Granthaalayah, 6(12), 135-139. 10.29121/granthaalayah.v6.112.2018.1098.
\end{abstract}

\section{Introduction}

A discharge that only bridges part of the space between two conducting elements. Partial Discharge is one of the predominant drivers of long-term degradation and eventual failure of electrical insulation. The PD energy dissipates mostly as heat, but also as sound and light. Insulation materials degrade when overheated. Although the partial discharge energy can be small, it can take place in the same location hundreds or thousands of times per second. The effect of partial discharge is severe to the insulation system of high voltage power equipment. Damage of insulation occurs due to generation of partial discharge and the conductive properties of the insulating material rises due to chemical changes in the dielectrics such as inorganic and organic. The polymers are organic dielectrics. Partial discharges generate the energy in the form of heat and the heat energy is the main reason for degradation of the insulation. Therefore, these effects are known as thermal effect on insulating material. 


\section{Results and Discussion}

The capacitance value for epoxy resin $\left(\varepsilon_{\mathrm{r}=3.4}\right)$ as $\mathrm{C}_{\mathrm{a}}=5.2 \times 10^{-12} \mathrm{~F}, \mathrm{C}_{\mathrm{b}}=4.2 \times 10^{-13} \mathrm{~F}$ and $\mathrm{C}_{\mathrm{c}}=2.8 \times 10^{-}$ ${ }^{14} \mathrm{~F}$ is used for simulation in MATLAB. We are used the parameter is used in Simulink model after that we are finding out the value of partial discharge as $6 \times 10^{-4} \mathrm{PD}$ amplitude (V) shown in figure.2, when applied A.C. Voltage source as $11 \times 10^{3}(\mathrm{~V})$ using of capacitance value as $0.33 \times 10^{-}$ ${ }^{6} \mathrm{~F}$. After that we are finding out the value of partial discharge as $3 \times 10^{-3} \mathrm{PD}$ amplitude $(\mathrm{V})$ shown in figure.3, when applied A.C. Voltage source as $11 \mathrm{X}^{3} 0^{3}(\mathrm{~V})$ using of capacitance value as 0.47 $\mathrm{X} 10^{-6} \mathrm{~F}$. In this way, the value of partial discharge is low using of capacitance value as $0.47 \mathrm{X}^{-}$ ${ }^{6} \mathrm{~F}$, which is best result.

The capacitance value for vulcanized fibres $\left(\varepsilon_{\mathrm{r}}=2.5\right)$ as $\mathrm{C}_{\mathrm{a}}=5.0 \times 10^{-12} \mathrm{~F}, \mathrm{C}_{\mathrm{b}}=4.1 \times 10^{-13} \mathrm{~F}$ and $\mathrm{C}_{\mathrm{c}}=$ $2.8 \times 10^{-14} \mathrm{~F}$ is used for simulation in MATLAB. We are used the parameter is used in Simulink model after that we are finding out the value of partial discharge as $5 \times 10^{-4} \mathrm{PD}$ amplitude (V) shown in figure.4, when applied A.C. Voltage source as $11 \times 10^{3}(\mathrm{~V})$ using of capacitance value as $0.33 \times 10^{-6} \mathrm{~F}$. After that we are finding out the value of partial discharge as $2 \times 10^{-3} \mathrm{PD}$ amplitude (V) shown in figure.5, when applied A.C. Voltage source as $11 \mathrm{X} 10^{3}$ (V) using of capacitance value as $0.47 \times 10^{-6} \mathrm{~F}$. In this way, the value of partial discharge is low using of capacitance value as $0.47 \times 10^{-6} \mathrm{~F}$, which is best result.

The capacitance value for polyethylene $\left(\varepsilon_{\mathrm{r}}=2.2\right)$ as $\mathrm{C}_{\mathrm{a}}=4.9 \times 10^{-12} \mathrm{~F}, \mathrm{C}_{\mathrm{b}}=3.9 \times 10^{-13} \mathrm{~F}$ and $\mathrm{C}_{\mathrm{c}}=$ $2.8 \times 10^{-14} \mathrm{~F}$ is used for simulation in MATLAB. We are used the parameter is used in Simulink model after that we are finding out the value of partial discharge as $4.8 \mathrm{X} 10^{-4} \mathrm{PD}$ amplitude (V) shown in figure.6, when applied A.C. Voltage source as $11 \times 10^{3}(\mathrm{~V})$ using of capacitance value as $0.33 \times 10^{-6} \mathrm{~F}$. After that we are finding out the value of partial discharge as $2.5 \times 10^{-3} \mathrm{PD}$ amplitude (V) shown in figure.7, when applied A.C. Voltage source as $11 \mathrm{X} 10^{3}(\mathrm{~V})$ using of capacitance value as $0.47 \times 10^{-6} \mathrm{~F}$. In this way, the value of partial discharge is low using of capacitance value as $0.47 \times 10^{-6} \mathrm{~F}$, which is best result.

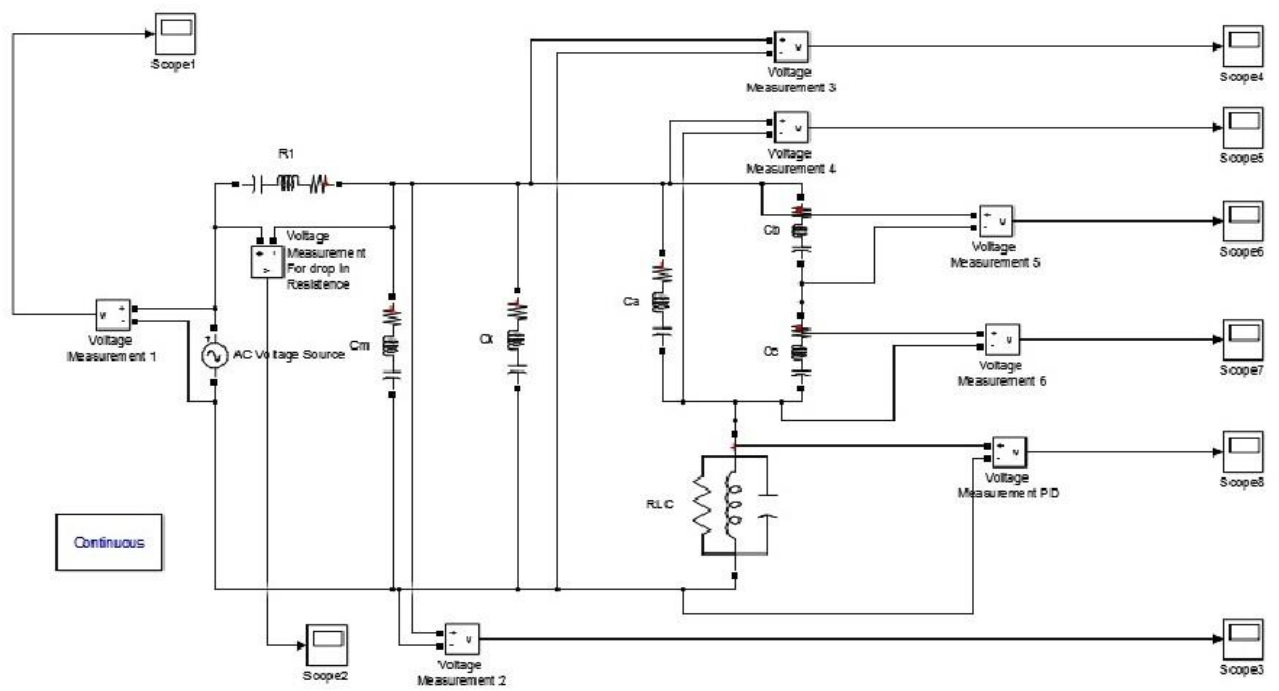

Figure 1: MATLAB Simulink model for PD measurement Parameters 


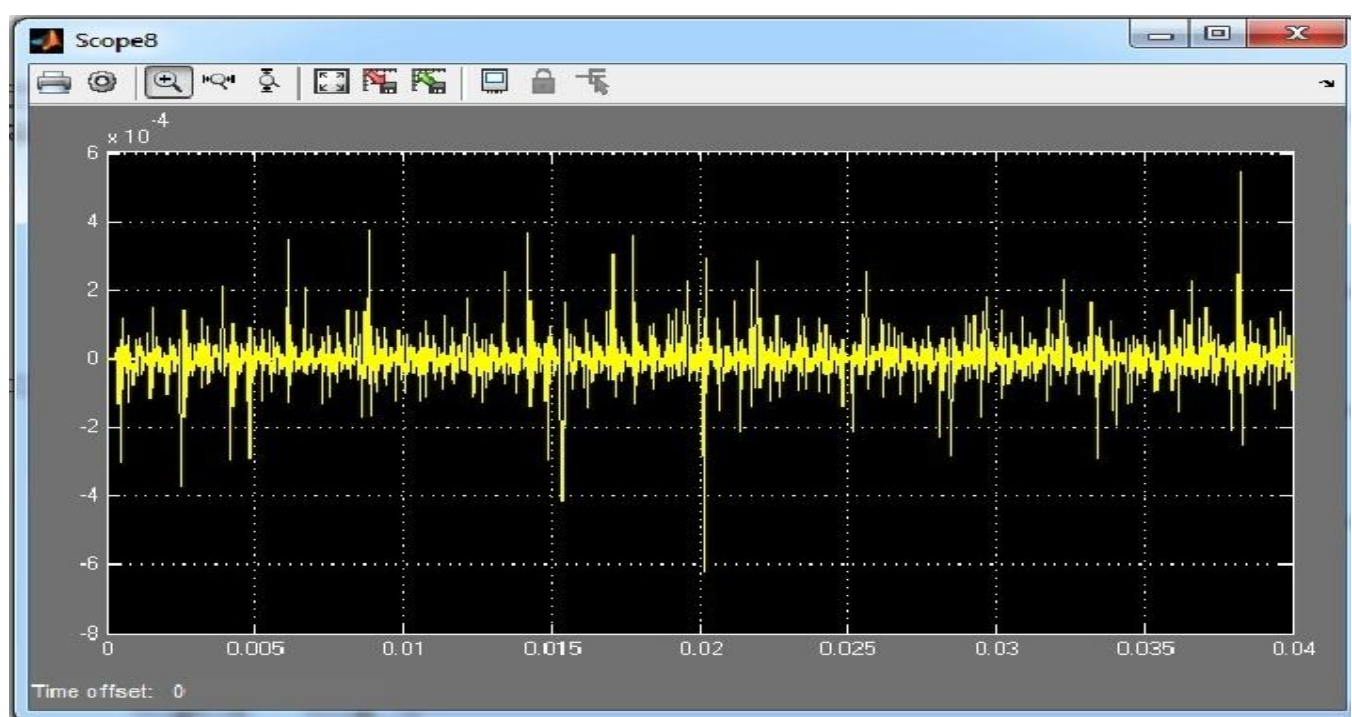

Figure 2: Value of partial discharge

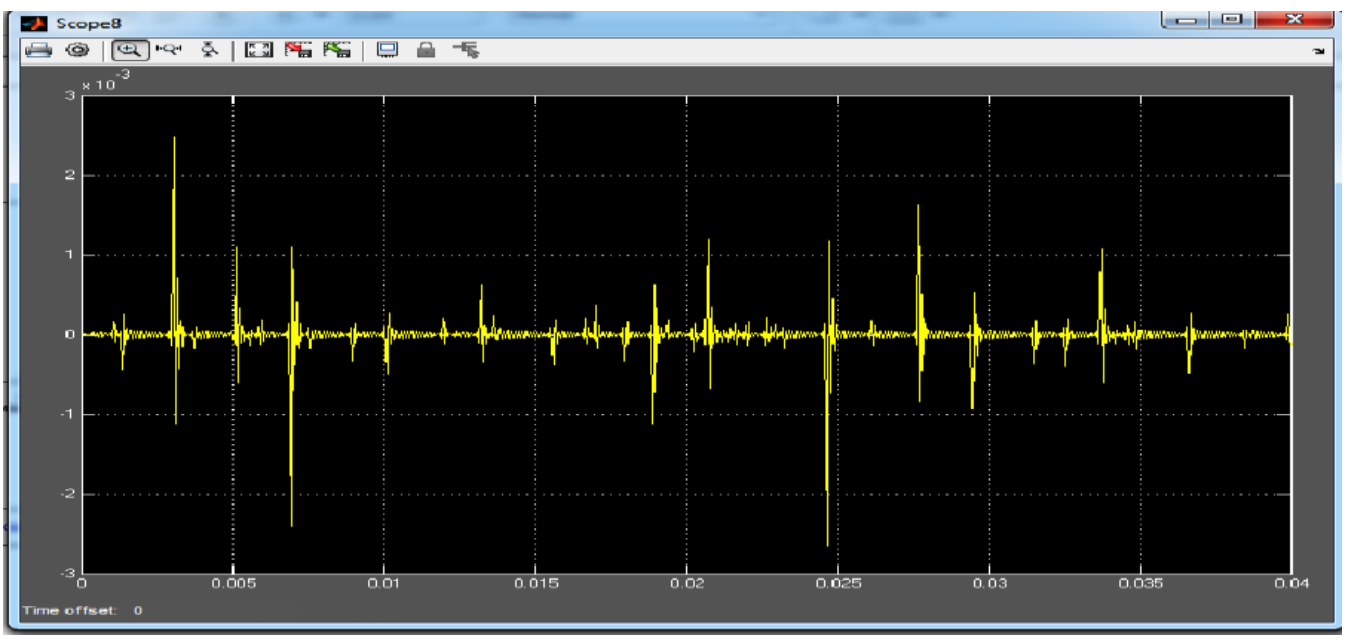

Figure 3: Value of partial discharge

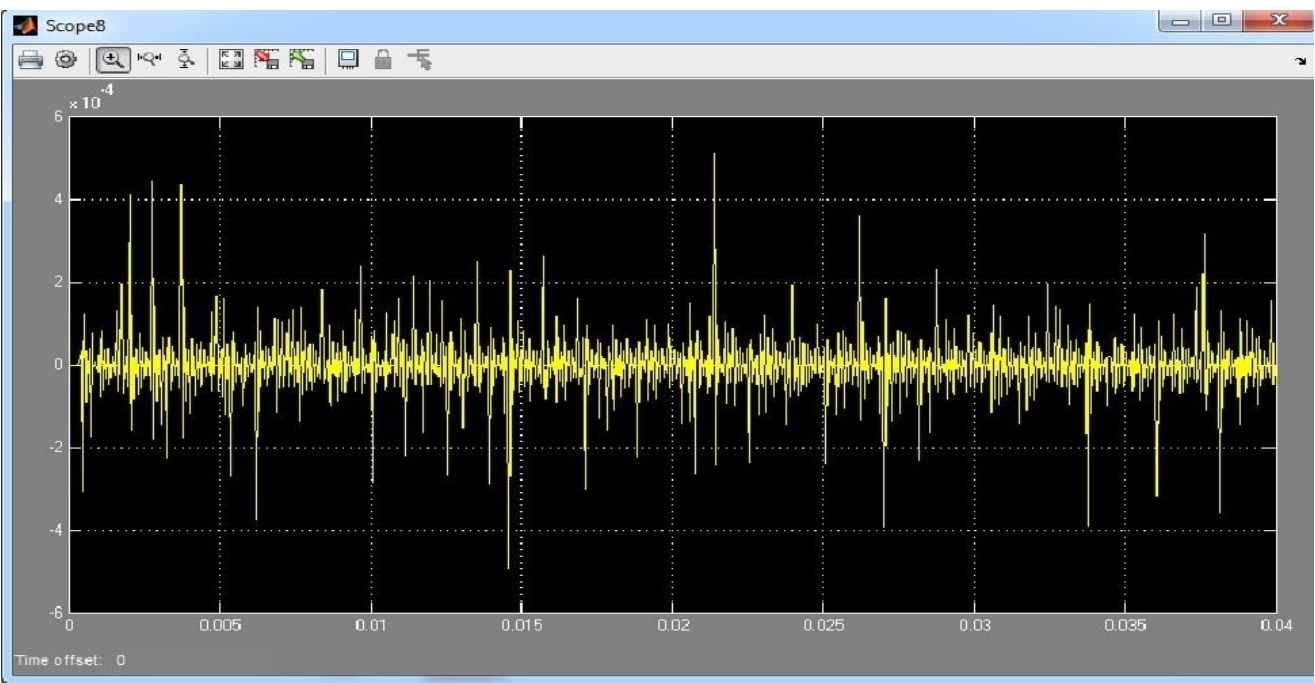

Figure 4: Value of partial discharge 


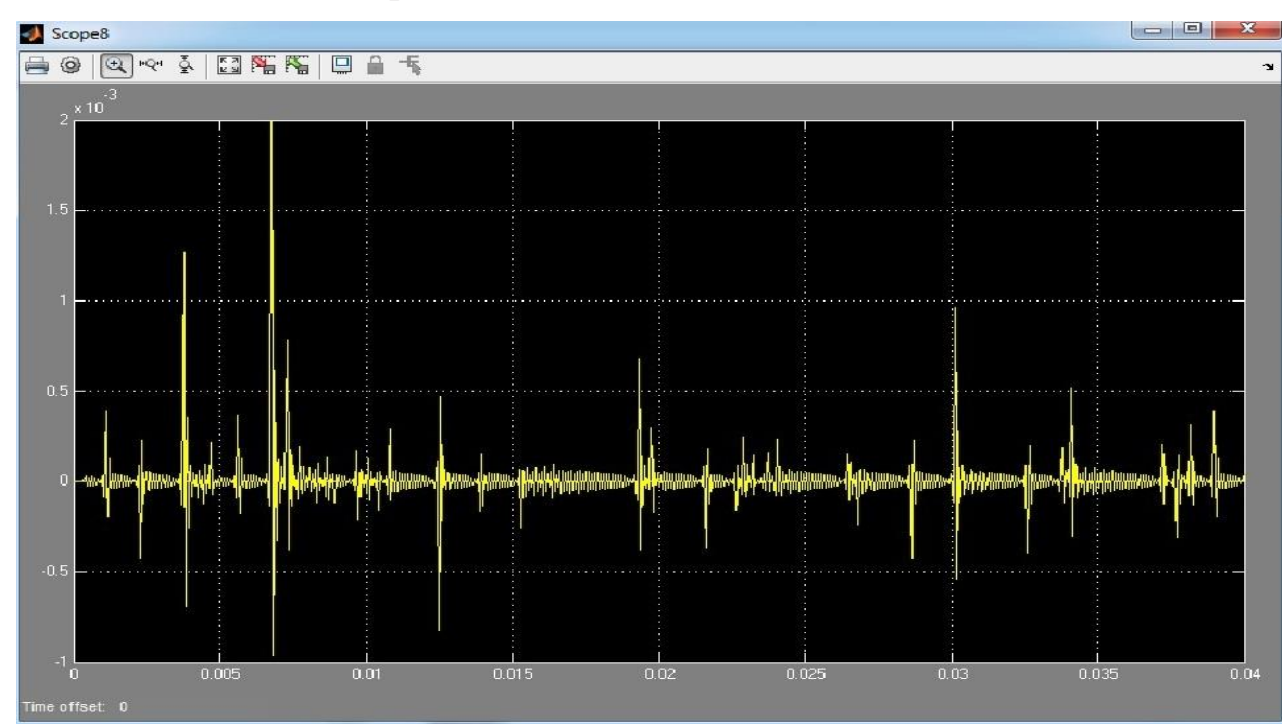

Figure 5: Value of partial discharge

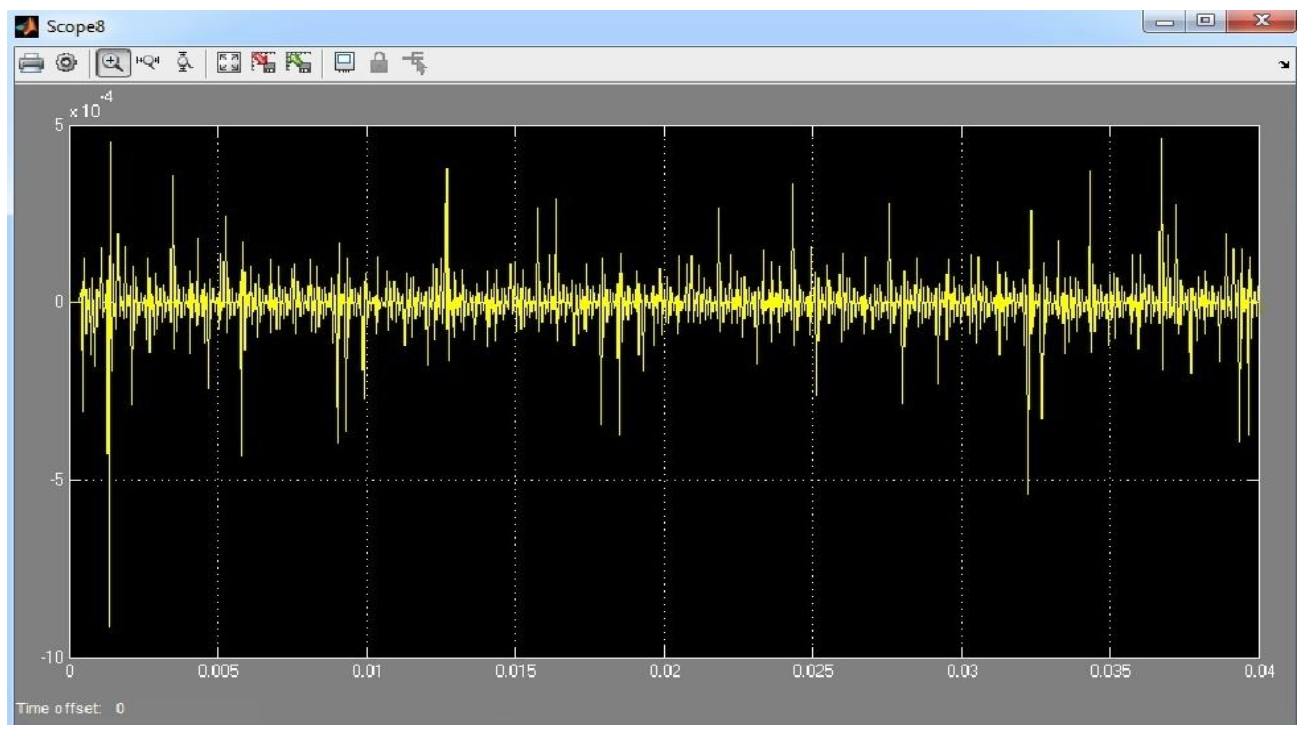

Figure 6: Value of partial discharge

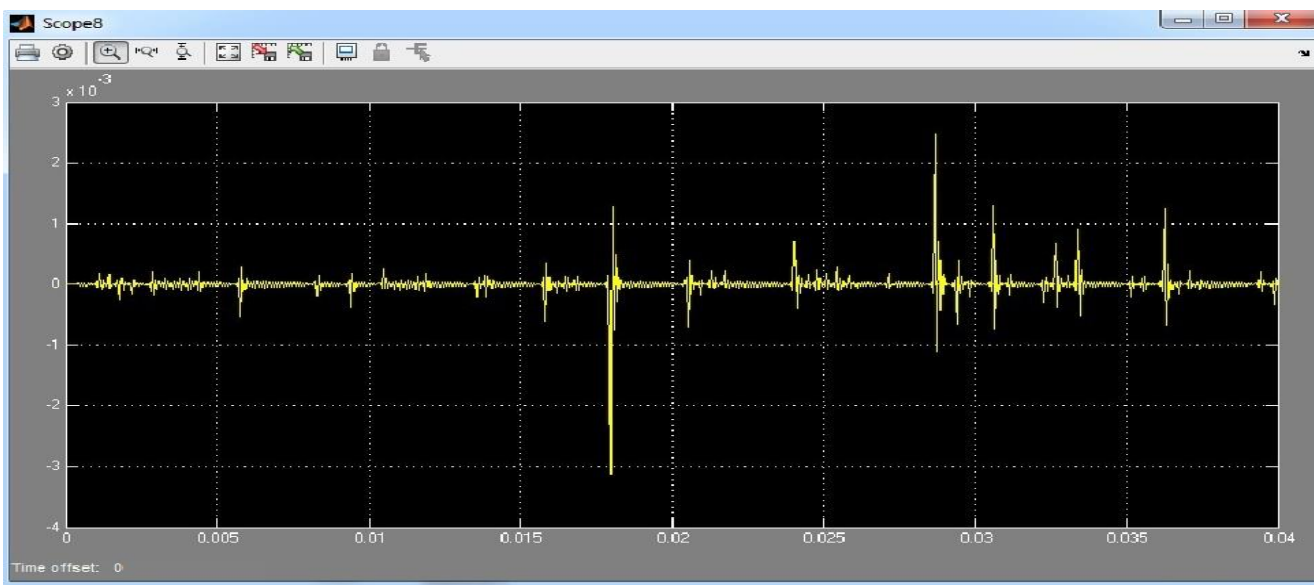

Figure 7: Value of partial discharge 


\section{Conclusion}

In this paper, three insulating material are considered such as epoxy resin $\left(\varepsilon_{\mathrm{r}=3.4}\right)$, vulcanized fibres $\left(\varepsilon_{\mathrm{r}}=2.5\right)$ and polyethylene $\left(\varepsilon_{\mathrm{r}}=2.2\right)$, which have different relative permittivity $\left(\varepsilon_{\mathrm{r}}\right)$. We are also used the different types of capacitor, the value of capacitance value are $0.33 \times 10^{-6} \mathrm{~F}, 0.47 \times 10^{-6} \mathrm{~F}$ in Simulink model, after that we are finding out the different value of partial discharge. The capacitance value for vulcanized fibres $\left(\varepsilon_{\mathrm{r}}=2.5\right)$ as $\mathrm{C}_{\mathrm{a}}=5.0 \times 10^{-12} \mathrm{~F}, \mathrm{C}_{\mathrm{b}}=4.1 \times 10^{-13} \mathrm{~F}$ and $\mathrm{C}_{\mathrm{c}}=$ $2.8 \times 10^{-14} \mathrm{~F}$ is used for simulation in MATLAB. we are finding out the value of partial discharge as $2 \times 10^{-3} \mathrm{PD}$ amplitude (V) shown in figure.5, when applied A.C. Voltage source as $11 \mathrm{X} 10^{3}(\mathrm{~V})$ using of capacitance value as $0.47 \times 10^{-6} \mathrm{~F}$. In this way, the value of partial discharge is low using of capacitance value as $0.47 \times 10^{-6} \mathrm{~F}$, which is best result.

\section{References}

[1] Harish, B. N., Harisha, K. S., Srinivasa, D. M.: 'Analysis study on partial discharge magnitudes to the parallel and perpendicular axis of a cylindrical cavity', International Journal of Engineering Trends and Technology, 2017, 45, (7), pp. 334-337.

[2] Sharma, P., Bhanddakkar, A.: 'Simulation model of partial discharge in power equipment', International Journal of Electrical and Electronics Research, 2015, 3, (1), pp. 149-155.

[3] Kuffel, E., Zaengl, W. S., Kuffel, J.: 'High voltage engineering: fundamentals' (Eleslever, 2005).

[4] Boggs, S. A.: 'Partial discharge. iii. cavity-induced PD in solid dielectrics', IEEE Electrical Insulation Magazine, 1990, 6, (6), pp. 11-16.

[5] Arief, Y. Z., Izzati, W. A., Adzis, Z.: 'Modeling of partial discharge mechanisms in solid dielectric material', International Journal of Engineering and Innovative Technology (IJEIT), 2012, 1, (4), pp. 315- 320. 